\title{
Calculation of Effective Rainfall in the Spring Maize Growing Period
}

\author{
Nana Han ${ }^{1(\bowtie)}$, Gangyan Lou ${ }^{2}$, Yangren Wang ${ }^{1}$, Qingyun Zhou ${ }^{1}$, Jianhua Jin ${ }^{1}$, \\ Songmin $\mathrm{Li}^{1}$, Lantao $\mathrm{Ye}^{1}$ \\ ${ }^{1}$ Department of Hydraulic Engineering, Tianjin Agricultural University, Tianjin, China, 300384 \\ \{hnn23144, wyrf,jinjh2010, yltao\} @163.com, \\ \{zhougyand, lisongmin228\}@126.com \\ ${ }^{2}$ Yellow River Water Resource Protection Institute, Zhengzhou, China, 450004 \\ 28693538 @qq. com
}

\begin{abstract}
Effective rainfall accurate determination can promote the technology development of planning crop irrigation, irrigation water management, irrigation and drainage design and highly efficient use of water resources. However, the effective rainfall will be affected by many factors, such as the characteristics of rainfall, characteristic of the crop's type and crop water consumption, soil characteristics and the way farming farmland management. In addition, geographical location, climatic conditions and other factors will also affect the calculation of effective rainfall. Thus, a reasonable calculation method of effective rainfall should be determined based on the specific conditions of the region. In this paper, based on the meteorological data of Changzhi in Shanxi, the effective rainfall in the spring maize growing period was calculated by the method of water balance, under different hydrological conditions and different irrigation. And then this paper applied this method to analyze the effective rainfall of spring maize and simulate daily soil water content. The results show that: with the increase of rainfall, effective rainfall decreases. With the increase of irrigation amount, effective rainfall gradually reduced. With the increase of crop water requirements, effective rainfall gradually increased. Therefore, this paper analyzes the relationship between effective rainfall and rainfall, irrigation and crop water requirement. The correlation coefficient is 0.802 . It is closely related. The simulated and measured values of the growing period of spring maize daily soil moisture better fit, weather in the irrigation or non-irrigation conditions. This verified the calculation method of the effective rainfall.
\end{abstract}

Keywords: effective rainfall $\bullet$ irrigation $\bullet$ crop water requirement $\cdot$ water balance

\section{Introduction}

After precipitation falling into the ground, if the rainfall intensity exceeds the infiltration capacity of the ground, the precipitation which more than infiltration capacity of the ground surface will form runoff. The remaining precipitation will infiltrate into the soil. After infiltration into the soil, a portion is stored in the soil of 
the root zone, and more than soil water storage capacity will form free-gravity water. It will migrate along the soil profile to the below of the root zone, under the action of gravity. Thus deep infiltration leak is formed. In determining a crop irrigation water requirement, it must be considered to provide effective rainfall precipitation. In the field of irrigation for dry crops, the effective rainfall is the part precipitation which to meet the needs of the crop evapotranspiration. Therefore rainfall should be deducted surface runoff and deep infiltration leak. Effective rainfall accurate determination can promote the development of crop irrigation, irrigation water management, irrigation and drainage planning, and efficient use of water resources. However, due to the characteristics of rainfall, characteristic of the crop and water consumption, the characteristics of the soil and the way farming farmland management and other factors will affect the effective rainfall. It is more difficult to analysis the effective rainfall.

The practical and convenient common methods of calculation the effective rainfall is as follows: direct determination in the field, the water balance method and empirical formula method. With computer technology application in irrigation, water balance method is the focus of current research. As atwardhan A.S. proposed two calculation methods and applicable conditions based on soil water balance model. Yang Yanshan proposed empirical formula which fit for calculation effective rainfall of western Inner Mongolia sandstorm farmland. Ma Jianqin proposed empirical coefficients method to calculate effective rainfall. There are many factors affect effective rainfall, such as geographical location, climatic conditions. Thus a reasonable calculation method should be determined based on the specific conditions of the region. In this paper, the effective rainfall was calculated based on the Shanxi meteorological data and information of local soil moisture spring maize. It has important practical significance for the local crop irrigation, irrigation and drainage planning and efficient use of water resources development and other aspects.

\section{Experiments and Methods}

\subsection{Experimental Cite}

The field experiment was conducted at the Changzhi of Shanxi province in China. Changzhi study area located in the southeast of Shanxi Province, the southern section of the Taihang Mountains. It's eastern at the junction of Handan and Anyang. It's bounded on the west by Linfen, the south by Jincheng, and the north by Jinzhong. Changzhi is located in east longitude 111 degrees 58'-112 degrees 44', latitude 35 degrees 49'-37 degrees $08^{\prime}$.

Spring maize growing season is from May 1 to September 21. The total growth days are 144 . The average temperature is $21.6{ }^{\circ} \mathrm{C}$, average rainfall is $389.5 \mathrm{~mm}$, average evaporation is $1008.5 \mathrm{~mm}$, sunshine hours is 932.8 hours, and frost-free period is 180 days. Soil texture is medium loam. Soil capacity is $1.47 \mathrm{t} / \mathrm{m}^{3}$. The field water holding capacity is $23.5 \%$ by weight of water content. The wilting water content is $6 \%$ by weight of water. The depth of groundwater is $20 \mathrm{~m}$. Spring maize 
water consumption is mainly determined by measuring soil moisture content of soil, and calculated by the method of water balance.

\subsection{Data Collection}

In this paper, the daily meteorological data of Shanxi Province Changzhi area were collected from the year of 1986 to 2012 . It includes the data of average wind speed, sunshine time number, minimum temperature, maximum temperature, average air temperature, rainfall and relative humidity. The rainfall frequency was analyzed based on the data. And it selected 5\%, 25\%, 50\%, 75\%, 95\% of five typical years. The local reference crop evapotranspiration were calculated by penman Monteith formula. This paper calculated the effective precipitation under the condition of different rainfall and different irrigation. And it analyzed the relationships between rainfall, irrigation, crop water demand and the effective rainfall.

\subsection{Parameters of the model}

The spring maize growing period was divided into four stages, in order to study the effective rainfall better. The first stage is the initial growth period (from May 1to May 25). The second stage is the rapid development period (from May 26 to January 4). The third is the middle growth stage (from July 5 to August 23). The last is the mature stage (from Aug. 24 to Sept. 21).

The crop coefficient was determined by the segment single method in growing period. The results are provided in table 1.

Table 1. The table of spring maize crop coefficient in the growing period

\begin{tabular}{ccccc}
\hline Stage & $\begin{array}{c}\text { Initial growth } \\
\text { period }\end{array}$ & $\begin{array}{c}\text { Rapid } \\
\text { development period }\end{array}$ & $\begin{array}{c}\text { Middle } \\
\text { growth stage }\end{array}$ & $\begin{array}{c}\text { Mature } \\
\text { stage }\end{array}$ \\
\hline $\begin{array}{c}\text { Crop } \\
\text { coefficient }\end{array}$ & 0.36 & $0.36-1.16$ & 1.16 & $1.16-0.35$ \\
\hline
\end{tabular}

\subsection{Methods}

\subsubsection{Calculation of effective rainfall}

As dry crops throughout the growing period concerned, in the moist soil layer, and in any period of time $[0, t]$, the water balance equation can be expressed as follows.

Where:

$$
W_{\mathrm{t}}=\mathrm{P}_{\mathrm{f}}+\mathrm{K}+\mathrm{M}-\mathrm{ET}+\mathrm{W}_{0}
$$

$\mathrm{W}_{0}$ - soil water storage of unit area in the moist soil layer, at the initial periods, $\mathrm{mm}$; $\mathrm{W}_{\mathrm{t}}$ - soil water storage of unit area in the moist soil layer, at the end of periods, $\mathrm{mm}$; $\mathrm{P}_{\mathrm{f}}$ - effective rainfall of unit area, $\mathrm{mm}$;

$\mathrm{K}$ - the quantity of groundwater recharge, $\mathrm{mm}$. In this paper, the value of $\mathrm{K}$ is zero, because the local groundwater depth is deeper.

$\mathrm{M}$ - irrigation quantity of unit area, $\mathrm{mm}$; 
ET - actual crop evapotranspiration of unit area, $\mathrm{mm}$.

Effective rainfall refers to the water after rainfall minus the surface runoff and deep leakage, which can be effectively used for field crops. Effective rainfall is generally calculated using the following formula:

$$
\mathrm{P}_{\mathrm{f}}=\mathrm{P}-\mathrm{P}_{\mathrm{r}}-\mathrm{P}_{\mathrm{d}}
$$

Where:

$P$ - precipitation, $\mathrm{mm}$;

$P_{r}$ - surface runoff, $\mathrm{mm}$;

$P_{d}$-deep leakage, $\mathrm{mm}$.

Because the surface runoff is difficult to occur in the local field, the effective rainfall is the precipitation that removed underground deep leakage.

\subsubsection{Regression analysis}

This paper uses the linear regression method to establish an effective rainfall relationship with the total precipitation, irrigation and crop water requirement in the crop growing season.

$$
P_{f}=a_{0}+a_{1} P+a_{2} M+a_{a} E_{m}
$$

Where:

$P_{f}$ - the total effective rainfall in the whole growing period, $\mathrm{mm}$;

$P$ - the total actual rainfall in the whole growing period, $\mathrm{mm}$;

$M$ - the total irrigation water in the whole growing period, $\mathrm{mm}$;

ETm - the total crop water requirement in the whole growing period, mm.

$a_{0,} a_{1}, a_{2}, a_{3}-$ undetermined coefficients.

\section{Results and Discussion}

\subsection{Rainfall Frequency Analysis}

Based on the daily rainfall data from the year of 1986 to 2012 in Changzhi area, the data of rainfall in the spring maize growing season were statistical analyzed year by year. And then the rainfall in the spring maize growing period was performed frequency analysis. The results are shown in table 2 .

Table 2. the typical year and rainfall

\begin{tabular}{ccc}
\hline Frequency & Year & Rainfall $(\mathrm{mm})$ \\
\hline $5 \%$ & 1988 & 575.7 \\
$25 \%$ & 2005 & 477.1 \\
$50 \%$ & 2002 & 371.8 \\
$75 \%$ & 2008 & 354.7 \\
$95 \%$ & 1997 & 199.5 \\
\hline
\end{tabular}

This paper takes five different typical frequency rainfalls. The frequencies separately are the $5 \%, 25 \%, 50 \%, 75 \%$, and $95 \%$. With the increase of frequency, the quantity of rainfall is decrease.

This paper studied the effective rainfall in this different typical frequency. 


\subsection{Effective rainfall analysis}

When the frequency rainfall is certain, the effective rainfall is calculated in different irrigation. Because the crop water requirement was different in these typical years, the relationship of effective rainfall with the precipitation, irrigation and the crop water requirement was studied. In order to study easily, each time the amount of irrigation water is the same. Single irrigation amount was $75 \mathrm{~mm}$. Irrigation times and irrigation dates were shown in Table 3.

Table 3. Irrigation times and irrigation dates

\begin{tabular}{|c|c|c|c|c|c|}
\hline \multirow[b]{2}{*}{$\begin{array}{l}\text { Irrigati } \\
\text { on times }\end{array}$} & \multicolumn{4}{|c|}{ Irrigation dates in spring maize growing period(month. day) } & \multirow[b]{2}{*}{$\begin{array}{r}\text { Irrigation } \\
\text { quota }(\mathrm{mm})\end{array}$} \\
\hline & $\begin{array}{l}\text { Initial } \\
\text { growth } \\
\text { period }\end{array}$ & $\begin{array}{c}\text { Rapid } \\
\text { development } \\
\text { period }\end{array}$ & $\begin{array}{l}\text { Middle } \\
\text { growth } \\
\text { period }\end{array}$ & $\begin{array}{l}\text { Mature } \\
\text { period }\end{array}$ & \\
\hline 1 & & & 7.6 & & 75 \\
\hline 2 & 5.25 & & 7.21 & & 150 \\
\hline 3 & 5.21 & 6.29 & 7.26 & & 225 \\
\hline 4 & 5.21 & 6.15 & $7.16,7.31$ & & 300 \\
\hline
\end{tabular}

The effective rainfalls were calculated in spring maize growing period day by day under the different typical years and different irrigation water, using the water balance method. And the total effective rainfall, precipitation, irrigation and crop water requirement were counted in the whole crop growing period. The results were provided in table 4. 
Table 4. The results of the total effective rainfall, precipitation, irrigation and crop water requirement in the whole crop growing period

\begin{tabular}{|c|c|c|c|c|c|c|}
\hline $\begin{array}{l}\text { Typical } \\
\text { frequency }\end{array}$ & $\begin{array}{l}\text { Irrigatio } \\
\text { n times }\end{array}$ & $\begin{array}{r}\text { Rainfall } \\
/ \mathrm{mm}\end{array}$ & $\begin{array}{l}\mathrm{ET}_{\mathrm{m}} \\
\quad / \mathrm{mm}\end{array}$ & $\begin{array}{l}\text { Irrigation } \\
\qquad / \mathrm{mm}\end{array}$ & $\begin{array}{l}\text { Effective } \\
\text { rainfall } \\
\qquad / \mathrm{mm}\end{array}$ & $\begin{array}{l}\text { Rainfall } \\
\text { utilization } \\
\text { coefficient }\end{array}$ \\
\hline \multirow{5}{*}{$5 \%$} & 0 & \multirow{5}{*}{575.7} & \multirow{5}{*}{366.4} & 0 & 401.8 & 0.698 \\
\hline & 1 & & & 75 & 327.4 & 0.569 \\
\hline & 2 & & & 150 & 274.1 & 0.476 \\
\hline & 3 & & & 225 & 226.0 & 0.393 \\
\hline & 4 & & & 300 & 124.9 & 0.217 \\
\hline \multirow{5}{*}{$25 \%$} & 0 & \multirow{5}{*}{477.1} & \multirow{5}{*}{433.3} & 0 & 455.3 & 0.954 \\
\hline & 1 & & & 75 & 405.6 & 0.850 \\
\hline & 2 & & & 150 & 353.0 & 0.740 \\
\hline & 3 & & & 225 & 292.4 & 0.613 \\
\hline & 4 & & & 300 & 213.7 & 0.448 \\
\hline \multirow{5}{*}{$50 \%$} & 0 & \multirow{5}{*}{371.8} & \multirow{5}{*}{404.0} & 0 & 371.8 & 1.000 \\
\hline & 1 & & & 75 & 371.8 & 1.000 \\
\hline & 2 & & & 150 & 336.7 & 0.906 \\
\hline & 3 & & & 225 & 247.7 & 0.666 \\
\hline & 4 & & & 300 & 187.0 & 0.503 \\
\hline \multirow{5}{*}{$75 \%$} & 0 & \multirow{5}{*}{354.7} & \multirow{5}{*}{385.8} & 0 & 354.7 & 1.000 \\
\hline & 1 & & & 75 & 324.7 & 0.915 \\
\hline & 2 & & & 150 & 276.2 & 0.779 \\
\hline & 3 & & & 225 & 220.6 & 0.622 \\
\hline & 4 & & & 300 & 151.5 & 0.427 \\
\hline \multirow{5}{*}{$95 \%$} & 0 & \multirow{5}{*}{199.5} & \multirow{5}{*}{467.3} & 0 & 199.5 & 1.000 \\
\hline & 1 & & & 75 & 199.5 & 1.000 \\
\hline & 2 & & & 150 & 199.5 & 1.000 \\
\hline & 3 & & & 225 & 199.5 & 1.000 \\
\hline & 4 & & & 300 & 158.1 & 0.792 \\
\hline
\end{tabular}

As can be seen from the table 4 , with the reduction in rainfall, effective utilization coefficient increases. While when the rainfall is the same, that is in the same typical year, with the increase of irrigation amount, the effective utilization coefficient is gradually reduced, and the effective utilization coefficient increases with the rain crop water demand increases. Thus the effective rainfall as the dependent variable, and the rainfall, irrigation and crop water requirements as the independent variable, the regression were analyzed according to all the values calculated. The results show that the correlation coefficient is 0.802 , and the relationship is closely. Its related equation as follows: 


$$
P_{f}=172.118+0.196 \mathrm{P}-0.597 \mathrm{M}+0.293 \mathrm{ET}
$$

According to the results, the effective rainfall numerical simulations were calculated. And then the correlation between the measured values and the simulated values of effective rainfall was analyzed. The results are shown in figure 1.

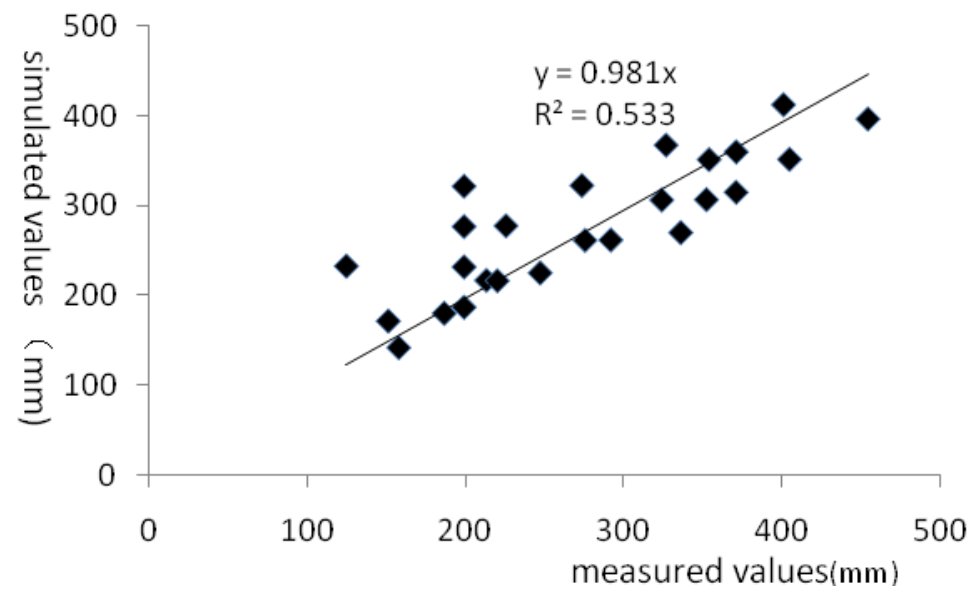

Fig.1. Relationship diagram of measured and simulated values of effective rainfall

As can be seen from the figure 1, the square of the correlation between simulated and measured value of effective rainfall is 0.533 . Thus the correlation coefficient is 0.73. It shows that the measured and simulated of effective rainfall has a good correlation. Based on the above results, it can be drawn that the water balance calculation method of effective rainfall is valid.

\subsection{Soil water storage measured and simulated values analysis}

Using the previously calculated effective rainfall method, this paper analyzed the measured and simulated soil water storage within 1.4 meters, taking the Zhangbei area's spring maize as an example.

\subsubsection{Soil water storage changes without irrigation}

Based on the measured soil water data of Zhangbei area in the condition of without irrigation, the simulated soil water data and measured data were analyzed. The results are provided in fig. 2 . 


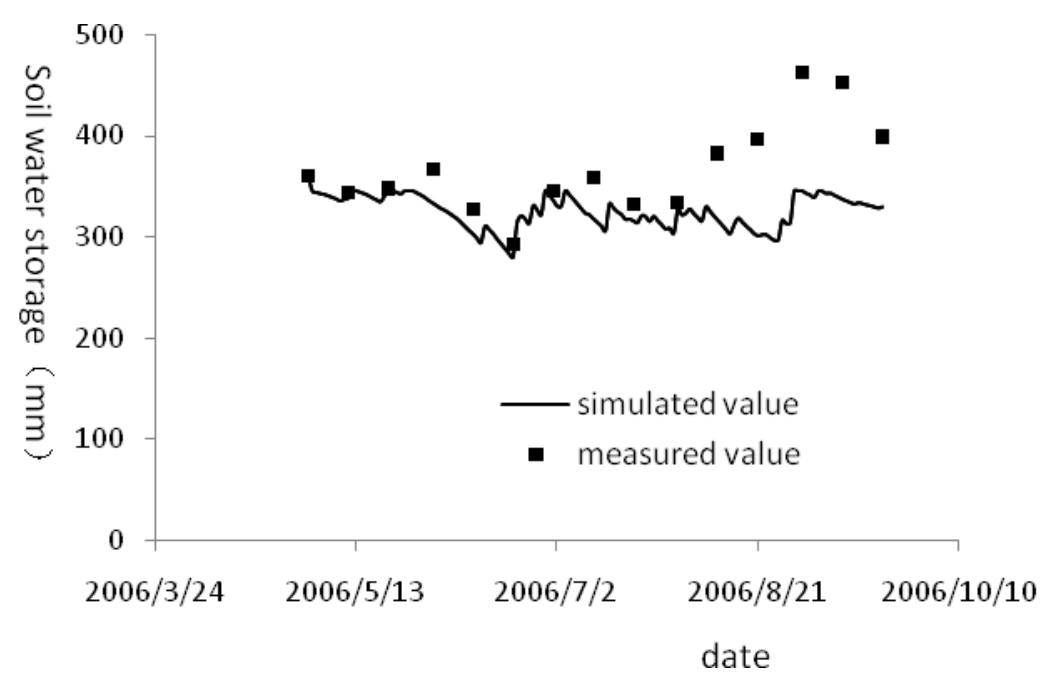

Fig.2. Comparison Chart of measured and simulated values of soil water storage without irrigation

It can be drawn from figure 2 that the simulated and measured values of soil water storage are more consistent in spring maize growing period, under the condition of without irrigation. While in the spring maize maturity period the measured value of soil water storage is slightly larger than the simulated value.

\subsubsection{Soil water storage changes with irrigation}

This paper analyzed the simulated and measured soil water storage change in the irrigation of $109 \mathrm{~mm}$. The irrigation time is one. The results are divided in figure 3 . From fig 3, it can be drawn that the simulated soil water storage fitting curves are well consonant with the observation data. It verified the approach of effective rainfall available and effective.

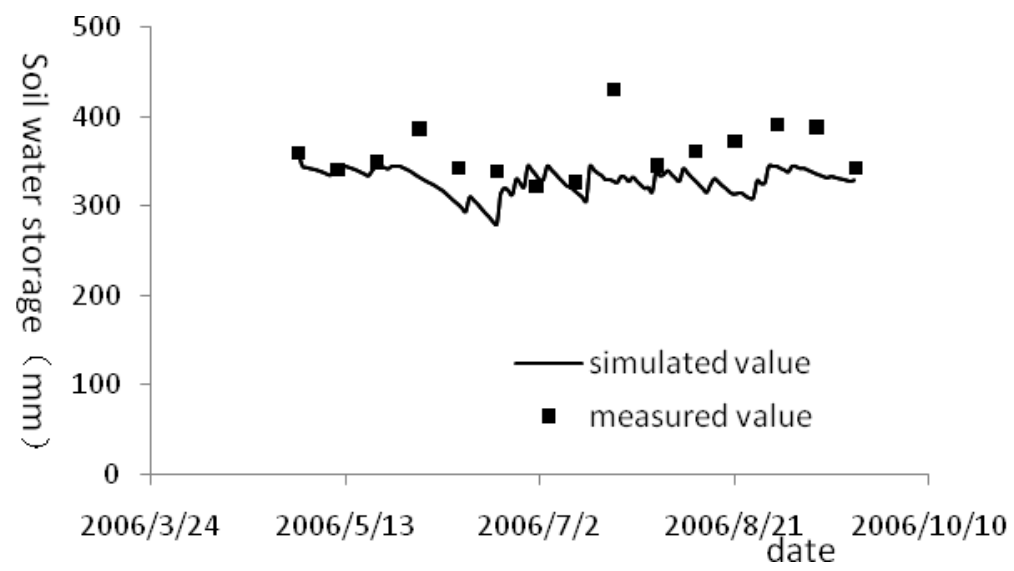


Fig.3. Comparison Chart of measured and simulated values of soil water storage with irrigation

\section{Conclusions}

The effective rainfall regression equation with the amount of irrigation, crop evapotranspiration, precipitation was established in the whole spring maize growing period. And the correlation coefficient was 0.802 . Therefore, effective rainfall and rainfall, irrigation and crop water demand is closely related.

In the same typical year, the deep leakage increases with the more irrigation times. At the same time the effective decreases. These figures showed that irrigation has greatly affected the effective precipitation.

This paper analyzed the simulated and measured values of spring maize soil water storage in Zhangbei area, using the effective rainfall method mentioned in the article. The results show that: under irrigation and non-irrigation conditions, soil simulated and measured values fit better, so the analysis method of effective rainfall is available and effective.

\section{References}

1. Patwardhan A S, Nieber J L,Johns E L.:Effective rainfall estimation methods. J IRRIG DRAIN ENG. 116 (2) :182-193(1990) .

2. Yang Yanshan, Chen Quchang, Guo Zhongxiao.: The Suitable Calculation Method of Effective Rainfall of Arable Land in Western Inner Mongolia Sandstorm Area. Inner Mongolia Hydrology. (1): 67-70(2004).

3. Ma Jianqin, Liu Lei, Zhang Zhenwei.:Agricultural Irrigation Water Theory of Real-time and Integrated Management System. Beijing: China Water and Power Press(2013).

4. Liu Zhandong, Duan Aiwang, Xiao Junfu.: Research Progress on Calculation Methods of Effective Rainfall in Growing Period on Dry Crop . Journal of Irrigation and Drainage. 26(3): 27-30(2007).

5. FW Chen, CW Liu, FJ Chang.: Improvement of the agricultural effective rainfall for irrigating rice using the optimal clustering model of rainfall station network. Paddy and Water Environment ,12 (4) :393-406(2014).

6. RG Babu, GR Babu , HVH Kumar.: Estimation of crop water requirement, effective rainfall and irrigation water requirement for vegetable crops using CROPWAT. International Journal of Agricultural Engineering , $8: 15-20(2015)$.

7. J Morábito, S Salatino, R Hernández. Et al.: Spatial distribution of reference crop evapotranspiration and effective rainfall in the central-northeastern provinces of Argentina. Revista de la Facultad de Ciencias Agrarias, 47 (1) :109-125(2015).

8. ZD Liu, AW Duan, JF Xiao, ZG Liu.: Research Progress on Calculation Methods of Effective Rainfall in Growing Period on Dry Crop. Journal of Irrigation and Drainage (2007).

9. Adnan S, Khan AH: Effective rainfall for irrigated agriculture plains of Pakistan. Pak J Meteorol ,6(11):61-72(2009).

10.Chen FW, Chen S, Tsai SM.: A study on deep ponding cultivation to estimate effective rainfall in Paddy Fields.Proceedings of the 2003 (2003). 
11.Kuo SF, Ho SS, Liu CW. : Estimation irrigation water requirements with derived crop coefficients for upland and paddy crops in ChiaNan irrigation association, Taiwan. Agric Water Manage ,82:433-451(2006).

12.Tekwa IJ, Bwade EK.: Estimation of irrigation water requirement of maize (zea-mays) using pan evaporation method in Maiduguri, Northeastern Nigeria. Agric Eng Int CIGR J 13(1):15(2011).

13.Tsai SM, Chen S, Wang HY.: A study on the practical model of planned effective rainfall for paddy fields in Taiwan. J Mar Sci Technol ,13(2):73-82(2005). 